The structural shift to green services: A twosector growth model with public capital and open-access resources

Emanuele Campiglio

December 2013

Centre for Climate Change Economics and Policy Working Paper No. 158

Grantham Research Institute on Climate Change and the Environment

Working Paper No. 141 
The Centre for Climate Change Economics and Policy (CCCEP) was established by the University of Leeds and the London School of Economics and Political Science in 2008 to advance public and private action on climate change through innovative, rigorous research. The Centre is funded by the UK Economic and Social Research Council and has five inter-linked research programmes:

1. Developing climate science and economics

2. Climate change governance for a new global deal

3. Adaptation to climate change and human development

4. Governments, markets and climate change mitigation

5. The Munich Re Programme - Evaluating the economics of climate risks and opportunities in the insurance sector

More information about the Centre for Climate Change Economics and Policy can be found at: http://www.cccep.ac.uk.

The Grantham Research Institute on Climate Change and the Environment was established by the London School of Economics and Political Science in 2008 to bring together international expertise on economics, finance, geography, the environment, international development and political economy to create a worldleading centre for policy-relevant research and training in climate change and the environment. The Institute is funded by the Grantham Foundation for the Protection of the Environment and the Global Green Growth Institute, and has five research programmes:

1. Global response strategies

2. Green growth

3. Practical aspects of climate policy

4. Adaptation and development

5. Resource security

More information about the Grantham Research Institute on Climate Change and the Environment can be found at: http://www.lse.ac.uk/grantham.

This working paper is intended to stimulate discussion within the research community and among users of research, and its content may have been submitted for publication in academic journals. It has been reviewed by at least one internal referee before publication. The views expressed in this paper represent those of the author(s) and do not necessarily represent those of the host institutions or funders. 


\title{
The structural shift to green services: A two-sector growth model with public capital and open-access resources
}

\author{
Emanuele Campiglio ${ }^{\mathrm{a}, 1}$ \\ ${ }^{a}$ Grantham Research Institute on Climate Change and the Environment \\ London School of Economics and Political Science (LSE) \\ Houghton Street, London, WC2A $2 A E$
}

\begin{abstract}
The expansion of the share of economic activity taking place in sectors with low or no impact on ecological resources is a crucial component of the transition to a low-carbon society. This "green" structural change is analyzed here by means of a growth model with a "progressive" manufacturing sector and a "stagnant" service sector. The latter - which I here name "green services" - represents an increasingly demanded class of activities characterized by high intensity of labour, reduced use of energy and low polluting emissions. Because of the non-substitutability of human participation these activities exhibit no labour productivity growth, while productivity in the manufacturing grows as a result of the presence of a stock of public capital (infrastructure) in its production function. The two sectors are also different in their impact on an open-access asset representing environmental quality, which enters the households welfare function. Along the Balanced Growth Path (BGP) a substitution process between consumption of the "dirty" manufactured good and the open-access asset takes place, leading to a stagnation in welfare despite the positive growth rate. Structural change occurs along the transition to the BGP. The share of employment in the service sector expands any time the initial value of the public-to-private capital ratio is above its BGP level. Finally, the role of infrastructure policies in shaping economy-environment interactions is discussed through a numerical example.
\end{abstract}

Key words: Structural change, green services, low-carbon economy, public capital, productivity, open-access resources

JEL: H54, O41, O44, Q50

\footnotetext{
${ }^{\text {th }}$ I would like to thank Luigi Bonatti, Giulia Felice and two anonymous referees for their useful comments. All errors are exclusively my own.

Email address: e.campiglio@lse.ac.uk (Emanuele Campiglio)

${ }^{1}$ Phone number: +447964913111
} 


\section{Introduction}

A transition to a low-carbon economic system is now widely considered essential and urgent (UNEP, 2011; OECD, 2011; World Bank, 2012a). A variety of human-induced ecological issues (Rockström et al., 2009), of which climate change is the most uncertain and potentially dangerous (Stern, 2006; IPCC, 2007), makes it necessary to shift to an economy characterized by low emissions of greenhouse gases and reduced material use.

Two main strategies can be adopted to achieve this. The first consists in accelerating the progress in clean technologies that can help decarbonise the economy, and especially the sectors responsible for the majority of emissions (manufacturing, transportation and production of energy). The second strategy is to expand the proportion of economic activity taking place in sectors having very low or no impact on environmental goods. This category includes not only the sectors actively involved in improving environmental resilience (production of energy from renewable sources, energy efficiency, water and waste management) but also those that, despite not directly contributing to the decarbonisation of the economy, tend to put a low pressure on material resources (for instance: education, arts, culture, sports).

This "green" structural change, which represents a crucial component of the transition to a sustainable economy, must be analysed taking into consideration the wider process of deindustrialisation interesting modern societies. The structural change towards the service sector, which now accounts for the wide majority of value added and employment in all high-income countries, is generally believed to have adverse consequences on growth rates because of the lower growth in labour productivity that service sectors typically exhibit (Baumol, 1967; Echevarria, 1997; Van Ark and Woltjer, 2008).

Structural change to a service-based economy is also usually indicated as one of the arguments at the basis of the Environmental Kuznets Curve (EKC) hypothesis, which pos- 
tulates the existence of an inverted-U relationship between environmental degradation and economic development (Kaika and Zervas, 2013). Given that services tend to be less material-based than manufacturing, expanding the proportion of economic activity in these sectors would help to dematerialise the economic system as a whole. This is confirmed by recent decomposition analysis (Voigt et al., 2014; Mulder and de Groot, 2012) although evidences are mixed and differ across countries and time periods.

This paper offers an original analytical framework capable of providing some insights on the features of the structural change to low-carbon services. The model presented is characterized by the presence of a "progressive" manufacturing sector and a "stagnant" service sector having: a) a different ability to increase labour productivity; b) a different impact on an open-access asset that enters the households welfare function. This can be interpreted alternatively as an index of environmental quality or as a measure for social capital and relational networks, both of which are likely to suffer from some kind of negative externality originated by market economic activity (Bartolini and Bonatti, 2002, 2008).

The service sector depicted here thus represents an increasingly demanded class of economic activities characterised by high intensity of labour, reduced consumption of energy, low polluting emissions and a strong attachment to the local economy. As a result of non-substitutability of human participation in the production process, these activities which I here name "green services" - tend to exhibit particularly low (or negative) growth rates in labour productivity. This is captured in the analytical framework by modelling the production function of the service sector as a function of sole labour.

The presence of the public actor in the transition to a low-carbon economy is crucial, in many respects. The most relevant for this paper is its role in the provision of public capital. As will be discussed in Section 2.3, the policy choices regarding infrastructure are likely to affect both the growth path of the economy and its environmental repercussions. 
In the model this is considered by introducing a stock of public capital into the production function of the progressive sector, which raises the marginal productivity of private capital. The different effect that public capital has on the sectors is what creates the productivity growth differential between them and ultimately drives structural change.

The analytical framework presented here is thus capable of analysing the effects of infrastructure policies on both growth and its interaction with ecological resources. This is particularly useful when a potential conflict exists between the long-run growth rate of the economy - accelerated by the presence of public infrastructure - and the the long-run level of welfare. The latter, while being improved by growth and higher consumption, is negatively affected by both environmental degradation and the amount of time dedicated to work.

The remainder of the paper is organised as follows.

Section 2 offers support to the assumptions made in the analytical framework. By providing empirical evidences the aim of the section is to argue that: a) service sectors, and those characterized by a higher intensity of labour in particular, exhibit lower labour productivity and lower labour productivity growth rates than manufacturing; b) the service sectors with high labour intensity tend to have a low impact on ecological resources; c) the choices taken by the public actor on infrastructure are likely to have strong effects on the economy growth rate and its environmental impact.

Section 3 presents the structure of the model. The economy is composed of two sectors, producing manufactured goods and green services. While manufactured goods are produced employing labour, private capital and public infrastructure, green services are produced by means of sole labour. Public capital enters the production function of manufactured goods raising the marginal productivity of private capital and creating a differential in productivity growth across the two sectors. The consumption of both manufactured 
goods and green services enter the welfare function of the representative agent, in combination with a stock variable representing environmental quality. The dynamics of this asset follows a logistic function and is negatively affected by the production of the manufacturing sector. Time off work (leisure) also is an argument of the utility function.

Section 4 derives the balanced growth path (BGP) of the economy and shows, for reasonable parameter values, its existence and saddle-path stability. Along the BGP private capital, public capital, the output of the manufacturing sector and the consumption of its goods all exhibit the same constant rate of growth. The output of the "stagnant" sector, on the other hand, doesn't grow at all. As a result, the share of physical output of the service sector gradually converges to zero, overshadowed by the ever increasing output of the manufacturing sector. However, since the relative price of services increases at the rate of physical capital, the nominal value of services also increases at the same rate and its share of aggregate GDP remains constant in the long-run. Employment levels in the two sectors remain stable. It can also be shown that whenever physical capital grows at a positive long-run growth rate the common resource asymptotically converges to zero. The depletion of the common resource is balanced by the increase in the consumption of the manufactured good. The substitution process that takes place generates a constant value of long-run utility.

Since along the BGP employment shares are constant, section 5 studies the transition of the system to the BGP - where employment shares are allowed to change - to discuss the features of the structural change to green services. I show that a shift of labour in direction of the stagnant clean sector takes place any time the initial value of the public-to-private capital ratio is above its BGP value.

Section 6 investigates the effects of a change in some relevant parameters to discuss the possibility of a conflict between the achievement of higher growth rates and the expansion of the level of welfare. In our numerical example both an increase in the tax rate and 
Figure 1: Share of services on total employment 1970-2008 3

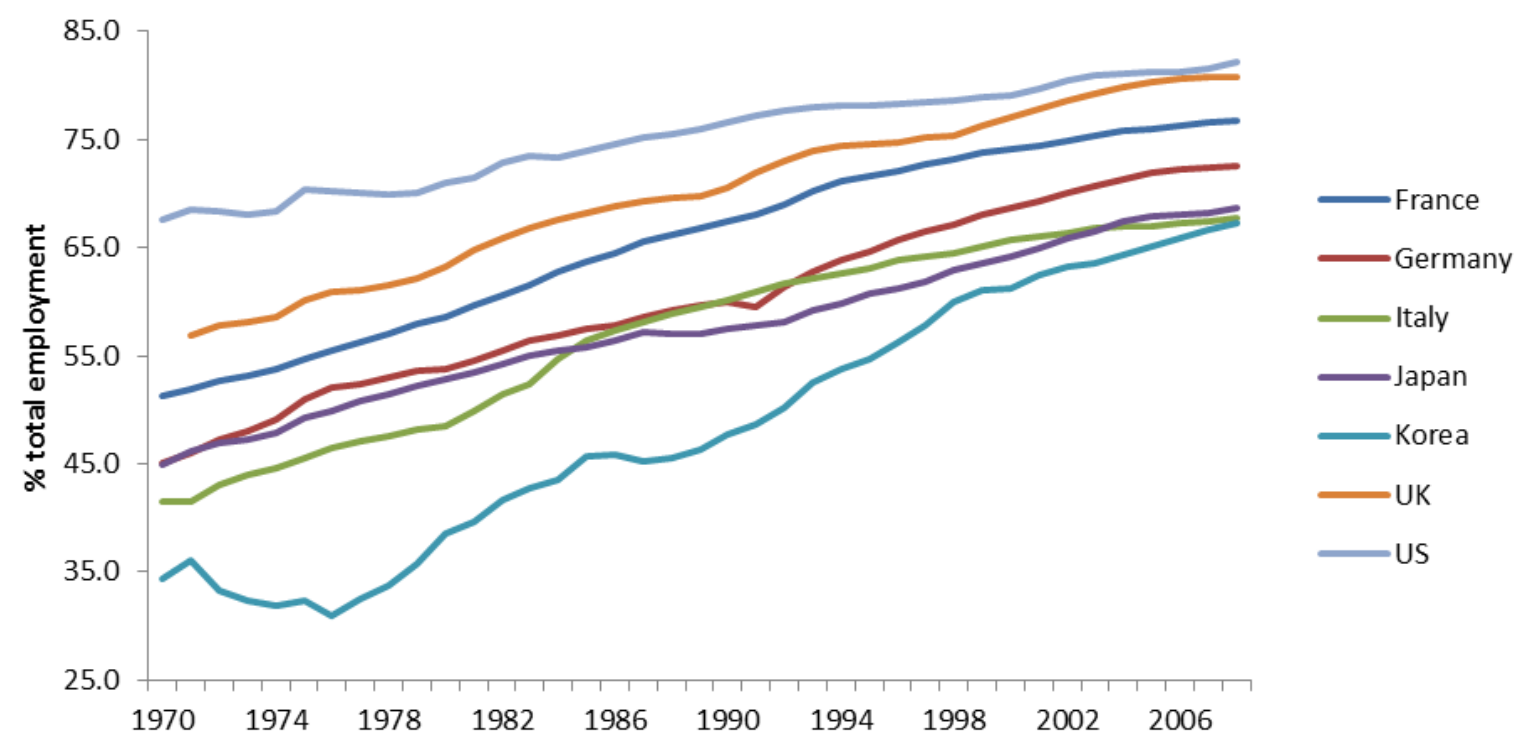

an increase in the parameter representing preferences for manufactured goods leads to a higher rate of growth along the BGP, while simultaneously reducing long-run welfare.

Finally, section 7 concludes.

\section{Motivation and literature}

\subsection{Structural change and productivity}

The gradual shift of production and employment towards services, which has been taking place in all high-income countries during the last decades, is a well-known fact. Figure 1 shows, for a selection of countries, how the share of services on total employment has been steadily expanding since $1970^{2}$.

\footnotetext{
${ }^{2}$ The process appears even clearer when looking at longer time-series (OECD, 1994).
} 
Unlike the structural change from agriculture to manufacturing industries, indicated as one of the main drivers of economic growth (Lewis, 1954), the subsequent shrink of manufacturing in favour of services seems to be at the heart of the recent decrease in high-income economies' growth rates. This is usually ascribed to the slower productivity growth experienced by service sectors (Baumol, 1967; Echevarria, 1997; Ngai and Pissarides, 2007).

Figure 2 reports data from the EU KLEMS Database on sectoral labour productivity growth in the EU-15 (Van Ark and Woltjer, 2008). In both time periods considered (19801995 and 1995-2005) the growth rate of labour productivity in the market service sector has been lower than the average growth rate in the aggregate market economy. Within services, the personal and social service sectors ${ }^{4}$, characterized by a pronounced content of labour, have exhibited a negative average growth rate of labour productivity during both periods. It is also interesting to notice how, in the same periods, the number of total hours worked in the personal and social service sectors has increased more than the average of all services, which in turn has shown a higher growth rate of hours worked than the overall market economy.

A similar pattern is exhibited by the United Kingdom (Acheson, 2011) and the United States (Van Ark et al., 2008). In both of them the service sector has experienced a lower productivity growth than the rest of the economy and the services characterized by a high labour content have performed particularly poorly. Additionally, the annual growth rate of total hours worked in both the personal and social service sector and the non-market service sector is higher than the one in the overall economy, denoting an expansion of the

\footnotetext{
${ }^{3}$ Source: STAN Database. Series EMPN (Number of people engaged). West Germany data is used for Germany before 1990 .

${ }^{4}$ In EU KLEMS this includes: Hotel and restaurants; Other community, social and personal services; Private Households with employed persons.

${ }^{5}$ Source: EU KLEMS Database (Van Ark and Woltjer, 2008).
} 
Figure 2: Growth in labour productivity and total hours worked (EU-15) ${ }^{5}$

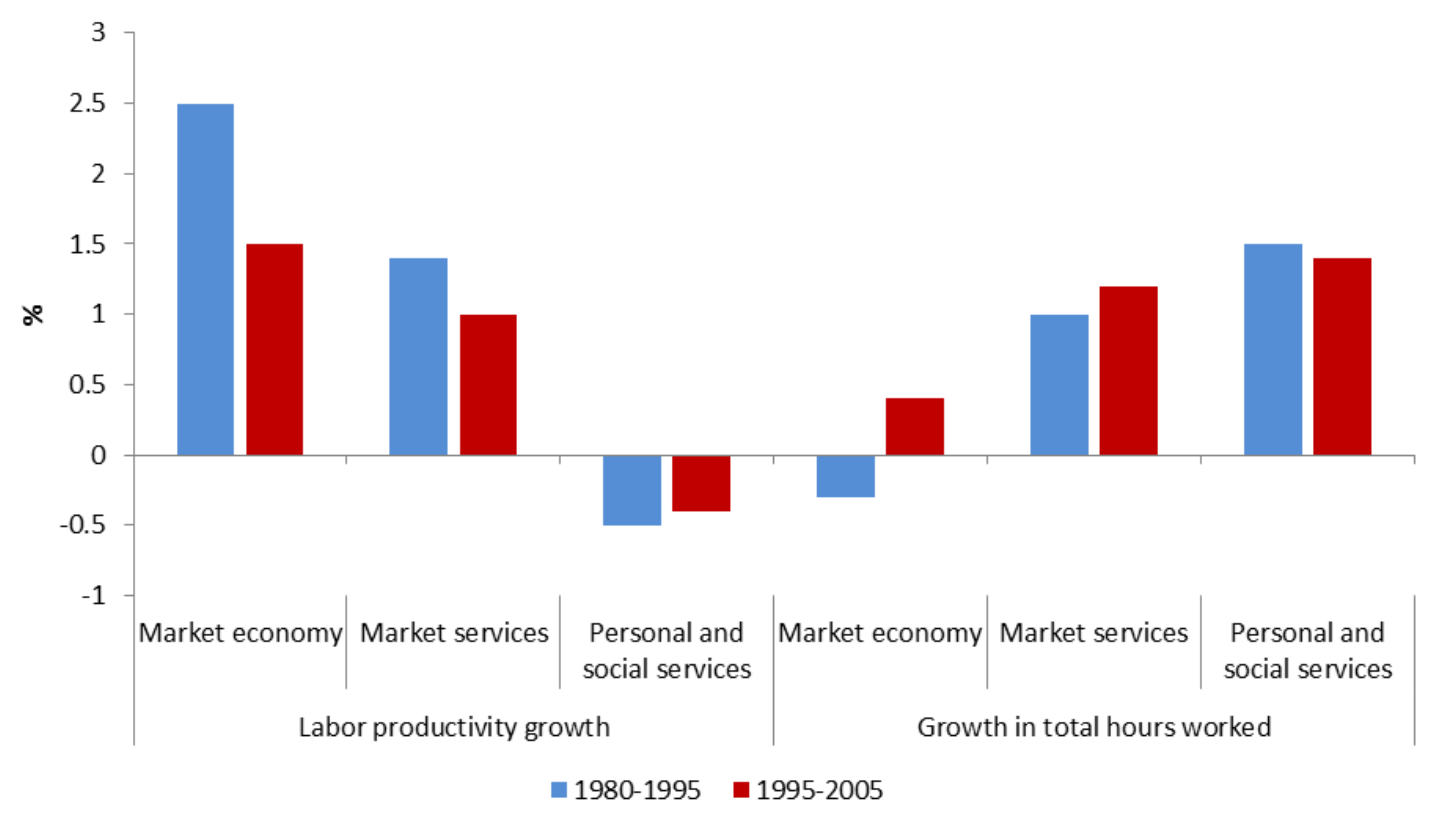

share of labour employed in those sectors.

Finally, McMillan and Rodrik (2011) point out how the sector of community, social, personal and government services is the one with the lowest level of labour productivity in five out of the nine high-income countries they analyse ${ }^{6}$. Also, the sector scores the lowest average labour productivity in the whole set of 38 developed and developing countries they take into account, with the exception of agriculture.

\subsection{The structural change to "green" services}

The previous section has argued that services sectors tend to be on average less productive and less incline to labour productivity growth than manufacturing, and that, within

\footnotetext{
${ }^{6}$ More precisely, the community, social, personal and government service sector is the one with the lowest labour productivity in France, Netherlands, Italy, Sweden and Denmark, while construction is the sector with lowest productivity in the US and in Spain, agriculture in Japan and whole and retail trade in the UK.
} 
services, the sectors characterized by high intensity of labour exhibit particularly low often negative - rates of productivity growth.

A similar variability exists with regards to the environmental impact of the service sector. Some services, most notably transportation and energy utilities, are major contributors to energy consumption and emission of greenhouse gases. This can be seen in Tables A.1 and A.2 (in Appendix A), which report the contribution of a selection of sectors to the total amount of UK emissions of greenhouse gases and its use of energy. What can also be appreciated inspecting the tables is how some other services - education, health and social work, arts, and other sectors with high labour intensity - have instead a very low impact on energy and climate.

This paper thus argues that a class of service-based economic activities - which I here call "green services" - can be identified, characterized by two main features: a) low material and energy intensity; b) high human intensity, and limited possibilities of labour productivity growth. Jackson and Victor (2011) include among the examples of green services “community energy projects, local farmers markets, slow food cooperatives, sports clubs, libraries, community health and fitness centres, gardening, local repair, maintenance and refurbishment services, craft workshops, writing centres, community music and drama, local training and skills, hairdressing, gardening, and conservation"7.

The classification of green services in terms of the International Standard Industrial Classification (ISIC, Revision 4) is not straightforward. A non-exhaustive list could include: Water supply; sewerage, waste management and remediation activities (Section E); Education (Section P) and in particular Sports and recreation education (Class 8541) and Cultural education (Class 8542); Human health and social work activities (Section Q),

\footnotetext{
${ }^{7}$ This vision is well embodied in civil society by the rapidly expanding "Transition Towns" movement, whose objective is the creation of resilient communities capable of proposing local responses to the interconnected challenges of climate change and the increasing scarcity of resources (Hopkins, 2011).
} 
and in particular Residential care activities (Class 87) and Social work activities without accommodation (Class 88); Arts, entertainment and recreation (Section R), and in particular Creative, arts and entertainment activities (Class 90), Libraries, archives, museums and other cultural activities (Class 91) and Sports activities and amusement and recreation activities (Class 93); Other service activities (Section S), and in particular Activities of membership organizations (Class 94), Repair of computers and personal and household goods (Class 95) and Other personal service activities (Class 96); Activities of households as employers; undifferentiated goods- and services-producing activities of households for own use (Section T).

It is evident how the labour input in the production of such services can only be reduced to a very limited extent, as it constitutes the inner value that qualifies the activity. Consequently, the potential improvement of productivity levels is very low. These services can be interpreted as an environmental-friendly equivalent of Baumol's "stagnant" sectors, in which, contrary to manufacturing, labour is not only an instrument of production but represents "an end in itself" and the quality of the service "is judged directly in terms of amount of labour" (Baumol, 1967).

Despite their low productivity, the share of employment in these sectors is expanding. Figure 3 shows the 5-year growth rate in both total employment and employment in green sectors - as defined above - for a variety of countries in the 2000-2005 and 2005-2010 periods. Its easy to see how, in all countries and for both periods, employment in green services has been increasing faster than the aggregate average (with the only exception of France in 2000-05), indicating a generalized expansion of these sectors in the last decade.

\footnotetext{
${ }^{8}$ Source: STAN Database. Green sectors here include: Water supply; sewerage, waste management and remediation activities (D36T39); Education (D85); Residential care and social work activities (D87T88); Arts, entertainment and recreation (D90T93); Other service activities (D94T96); Activities of households as
} 
Figure 3: Expansion of employment in"green" sectors 8

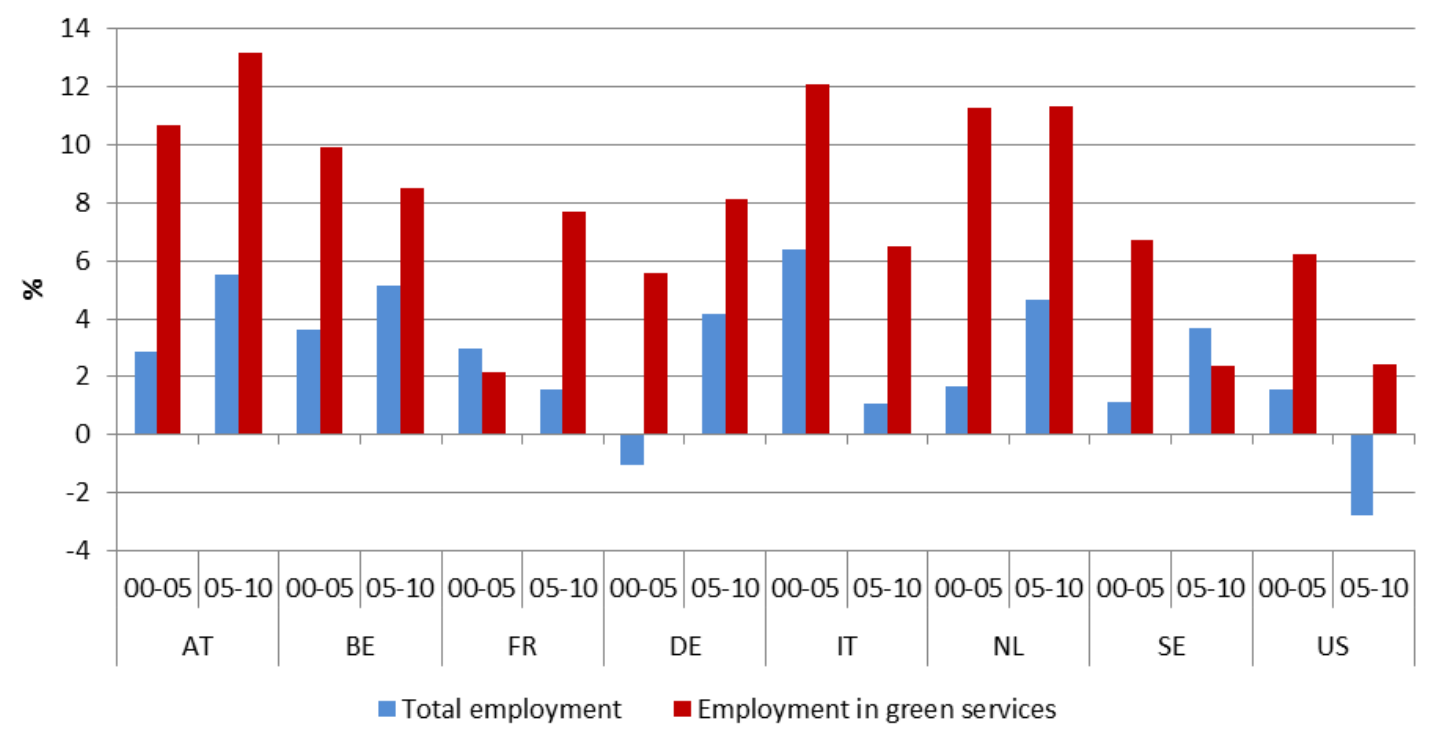

\subsection{The effect of infrastructure on growth and sustainability}

Both the labour productivity growth rate and the environmental resilience of an economic system are likely to be strongly affected by the behaviour of the public actor. In particular, and more importantly for this paper, the choices regarding the provision of infrastructure can have critical long-run consequences on how the economy is organised.

Public infrastructure has traditionally been considered as one of the fundamental drivers of growth and development (World Bank, 1994, 2012b). A transportation system facilitating access to the market and allowing movements of people and goods at moderate cost; an advanced information and communication technology (ICT) capable of connecting firms and accelerating transactions; a reliable energy production and distribution system; all these forms of public capital appear to be crucial preconditions for the improvement of private sector efficiency and the expansion of economic activity, both in high-income and

employers, undifferentiated goods- and services-producing activities of households for own use (D97T98). 
developing countries. In addition, the presence of infrastructure is generally considered beneficial for territorial equity and the economic integration of peripheral regions.

This view has led the development of infrastructure to be one of the main objectives of governments' action. For instance, the founding Treaty of the European Community - the 1957 Treaty of Rome - stated that the Community "shall contribute to the establishment and development of trans-European networks in the areas of transport, telecommunications and energy infrastructures." 9 . This intent was put into practice through the formulation and implementation of the Trans-European Networks (TENs), interconnected structures unifying European mobility (TEN-T), energy (TEN-E) and telecommunication (eTEN) systems. These networks are regarded as a necessary condition to achieve smart, sustainable and inclusive growth, main objective of the "Europe 2020" strategy (EC, 2010). Similar considerations are often made for developing regions as well, where the volume and quality of infrastructure are believed to play an important role in fostering growth and facilitating the end of poverty (Calderon, 2009; Calderon and Serven, 2010).

Decisions concerning public investments in infrastructure are also likely to have consequences on the interaction between the economic system and ecological resources, especially because of the strong path-dependence features of public capital and the danger of technological lock-ins. Choices regarding the type of infrastructure to build must be thus analysed considering the possible trade-offs arising between long-run growth - accelerated by the presence of public capital - and welfare, which can be damaged by the negative externalities produced. Bonatti and Campiglio (2013), for instance, show how a shift of public resources from collective to private mobility infrastructure can induce higher growth by influencing individuals' consumption habits and work attitudes, while concurrently creating the conditions - environmental degradation and longer working hours - to

\footnotetext{
${ }^{9}$ Article 154. The full text of the Treaty can be found at http://eur-lex.europa.eu.
} 
reduce long-run welfare.

The role of the government is introduced in the model through the presence a stock of public capital into the production function of the progressive manufacturing sector, so that an increase in infrastructure raises the sectoral technological index, similarly to Turnovsky (1997), Chatterjee et al. (2003), Agenor (2010) and Felice (2011). In particular, the model is similar to Felice (2011) in assuming that public capital is affecting different sectors unevenly. Since infrastructure tends to improve the tradability of goods and services, and being green services strongly rooted in the local economy and thus typically non-tradable, the stock of public capital plays no role in their production.

\section{The model}

I consider an economy in discrete time with an infinite time horizon. The economy is populated by three types of agents: households, firms and the government. Agents expectations are rational. I assume the existence of a "progressive" sector where total factor productivity is affected by the stock of public capital, and of a "stagnant" sector where labour is the only input and there is no productivity growth. The good produced in the progressive sector is used as the numeraire of the system. All markets are assumed to be perfectly competitive. In particular, it is assumed that labor is homogenous and can freely move across the two sectors.

\subsection{Households}

For simplicity and without loss of generality, I assume a constant and large number (normalised to one) of identical households who take into account the welfare and resources of their actual and prospective descendants. Following Barro and Sala-i-Martin (1994), I thus assume that the current generation maximises utility over an infinite time horizon. That is, although individuals have finite lives, the model considers the existence 
of immortal "dynasties". The period utility $U_{t}$ of the representative household is the following:

$$
U_{t}=\beta \ln \left(X_{t}\right)+(1-\beta) \ln \left(l_{t}\right), \quad 0<\beta<1
$$

where $X_{t}$ represents a flow of services generated by some household activity, and $l_{t}$ is the time that households devote to leisure. $X_{t}$ is produced by the representative household according to the following consumer technology:

$$
X_{t}=\left(R_{t} C_{t}\right)^{\mu} C_{S, t}^{1-\mu}, \quad 0<\mu<1
$$

where $R_{t}$ is an open-access resource that cannot be produced, $C_{t}$ is the consumption of the good produced in the progressive sector and $C_{S, t}$ is the consumption of the good produced in the stagnant sector.

Equation (2) can be interpreted in the following way. The representative household draws utility from the consumption of both manufactured goods $\left(C_{t}\right)$ and green services $\left(C_{S, t}\right)$. However, in order to be enjoyed, consumption needs to be combined with a common resource (environment, air, relational networks, social values, etc.) of which everyone can freely make use. The household can obtain utility if and only if $R_{t}, C_{t}$ and $C_{S, t}$ are all strictly positive. The presence of $R$ is particularly important for the consumption of the "dirty" manufactured good, since it is assumed that the consumption of green services $C_{S, t}$ already embodies some of the features that characterise $R_{t}$ (being low-carbon and rich of relational networks).

In each period $t$ the representative household chooses $\left\{C_{t}\right\}_{0}^{\infty},\left\{C_{S, t}\right\}_{0}^{\infty},\left\{L_{t}\right\}_{0}^{\infty}$ and $\left\{K_{t+1}\right\}_{0}^{\infty}$ in order to maximise:

$$
\sum_{t=0}^{\infty} \theta^{t} U_{t}, \quad 0<\theta<1
$$


subject to a budget and a time constraint:

$$
\begin{aligned}
& w_{t} L_{t}+r_{t} K_{t}+\pi_{C, t}+\pi_{S, t}+(1-\delta) K_{t} \geq C_{t}+P_{t} C_{S, t}+K_{t+1}+T_{t}, \quad 0<\delta<1 \\
& l_{t}+L_{t} \leq 1
\end{aligned}
$$

where $L_{t}$ is labour supply, $K_{t}$ are the productive assets (capital) held by the representative household in $\mathrm{t}, \theta$ is a time-preference parameter, $w_{t}$ is the wage rate, $r_{t}$ is the rental rate on capital, $\pi_{C, t}$ and $\pi_{S, t}$ are, respectively, the profits that the representative household gets from the firms operating in the progressive sector and from those operating in the stagnant sector (the households are assumed to be the owners of the firms), $\delta$ is the rate at which capital depreciates, $P_{t}$ is the relative price of the green good, and $T_{t}$ are the taxes paid to the government. Finally, notice that the households total time endowment is normalised to 1 .

\subsection{Production}

Two goods are produced in the economy in each period $t$ : a good $Y_{C, t}$ produced in the progressive sector and a good $Y_{S, t}$ produced in the stagnant sector. While $Y_{S, t}$ is entirely consumed, $Y_{C, t}$ can be consumed, reinvested in production or transferred to the government. In both sectors I assume the existence of a fixed and large number (normalised to one) of identical and perfectly competitive firms. Good $Y_{C, t}$ is produced according to the following technology:

$$
Y_{C, t}=\left(\frac{K_{G, t}}{K_{t}}\right)^{\alpha} K_{t} L_{C, t}^{\alpha}, \quad 0<\alpha<1
$$

where $K_{t}$ is the amount of capital rent by the representative firm operating in the progres-

sive sector, $L_{C, t}$ is the amount of labour used in the production of $Y_{C, t}$ and $K_{G, t}$ represents the public capital stock. The functional form of the production function used here is similar to Turnovsky (1997), Chatterjee et al. (2003), Agenor (2010) and Felice (2011). An 
increase in the stock of public capital shifts the production function upwards, thus raising the productivity of private capital, though at a diminishing rate. Transport infrastructure is a typical example: a well developed network of highways and railways facilitates the movement of both final and intermediate goods and services thus lowering production costs. Similar considerations can be applied to ICT networks and energy infrastructure. Alternatively, public capital can be considered as a third factor of production ${ }^{10}$.

In each period, the representative firm operating in the progressive sector employs labour and rents capital in order to maximise its profits $\pi_{C, t}$, where:

$$
\pi_{C, t}=Y_{C, t}-w_{t} L_{C, t}-r_{t} K_{t}
$$

Good $Y_{S, t}$ is produced according to the following technology:

$$
Y_{S, t}=L_{S, t}
$$

where $L_{S, t}$ is the amount of labour employed in the stagnant sector.

As discussed in section 2.2, $Y_{S, t}$ can be interpreted as those services for which human labour constitutes the crucial input that creates utility. These are typically services produced, exchanged and consumed at a community level, thus involving a relatively small deployment of both private and public physical capital. Improvements of transport and energy infrastructure thus have a negligible impact on the productivity of the sector producing these services, which can legitimately treated as stagnant. These services also usually require a very low use of material and energetic resources when compared to the manufacturing sector, thus allowing me to classify them as "green".

The profits $\pi_{S, t}$ of the representative firm in the green service sector are:

$$
\pi_{S, t}=P_{t} Y_{S, t}-w_{t} L_{S, t}
$$

\footnotetext{
${ }^{10}$ As argued by Romp and de Haan (2007) the two interpretations are equivalent when a Cobb-Douglas technology is used.
} 


\subsection{The government}

The government invests a fixed fraction $\tau$ of the value added generated by the progressive sector in the creation of public capital. This investment is entirely financed by the tax revenues. Thus, the stock of public infrastructure evolves according to:

$$
K_{G, t+1}=\tau Y_{C, t}+(1-\delta) K_{G, t}
$$

where

$$
\tau Y_{C, t}=T_{t}
$$

Notice that for simplicity and without loss of generality the rate of depreciation of $K_{G, t}$ is assumed to be identical to the depreciation rate of private capital.

\subsection{The common resource}

The representative household derives utility from the existence of an environmental asset $R_{t}$, whose stock is negatively affected by the production of the progressive good $Y_{C, t}$. In particular we specify the following functional form for the dynamics of $R_{t}$ :

$$
R_{t+1}-R_{t}=\chi R_{t}\left(1-\frac{R_{t} Y_{C, t}}{E_{0}}\right), \quad \chi>0, E_{0}>0, R_{0} \text { given } .
$$

where $\chi$ represents the intrinsic growth rate of the resources and $E_{0}$ is the carrying capacity of the environment. Equation (12) is a modified version of the logistic growth function, a widely used functional form to describe the dynamics of renewable resources. It is here adjusted through the introduction of the output of the manufacturing sector in a way that a higher production of $Y_{C, t}$ negatively affects the evolution of $R$. 


\subsection{Market-clearing conditions}

Equilibrium in the product markets requires, respectively:

$$
(1-\tau) Y_{C, t}=C_{t}+K_{t+1}-(1-\delta) K_{t}
$$

and

$$
Y_{S, t}=C_{S, t}
$$

Equilibrium in the labour market requires:

$$
L_{t}=L_{C, t}+L_{S, t}
$$

Equilibrium in the capital market requires:

$$
K_{t}^{s}=K_{t}^{d}
$$

where $K_{t}^{s}$ is the capital supplied by the households in period $t$ and $K_{t}^{d}$ is the capital demanded by the firms operating in the progressive sector.

\section{The balanced growth path}

In a perfectly competitive equilibrium, the rental rate on capital $r_{t}$ to capital is equal to its marginal productivity:

$$
r_{t}=(1-\alpha)\left(\frac{K_{G, t}}{K_{t}}\right)^{\alpha} L_{C, t}^{\alpha}
$$

In equilibrium, the following condition regarding the wage rate $w_{t}$ must hold:

$$
w_{t}=\alpha L_{C, t}^{\alpha-1}\left(\frac{K_{G, t}}{K_{t}}\right)^{\alpha} K_{t}=P_{t}
$$

Given the linear production function of $Y_{S, t}$, the relative price of green services $P_{t}$ in a competitive equilibrium is equal to the wage rate $w_{t}$. 
By solving the households' optimisation problem it is possible to find a system of three difference equations in $Q_{t} \equiv\left(\frac{K_{G, t}}{K_{t}}\right), Z_{t} \equiv R_{t} K_{t}$ and $L_{t}$, that governs the equilibrium path of the economy (see Appendix B):

$$
\begin{gathered}
\Phi\left(Q_{t+1}, Q_{t}, L_{t}\right)=Q_{t+1}\left[1+\omega_{K}\left(Q_{t}, L_{t}\right)\right]-t\left[Q_{t} f\left(L_{t}\right)\right]^{\alpha}-(1-\delta) Q_{t}=0 \\
\Lambda\left(Z_{t+1}, Q_{t}, L_{t}, Z_{t}\right)=\frac{Z_{t+1}}{1+\omega_{K}\left(Q_{t}, L_{t}\right)}-Z_{t}-\chi Z_{t}\left(1-\frac{Z_{t}\left[Q_{t} f\left(L_{t}\right)\right]^{\alpha}}{E_{0}}\right)=0 \\
\Psi\left(Q_{t+1}, L_{t+1}, Q_{t}, L_{t}\right)=\frac{Q_{t}^{\alpha}\left(1-L_{t}\right)}{\left[f\left(L_{t}\right)\right]^{1-\alpha}} \theta\left\{1-\delta+(1-\alpha) Q_{t}^{\alpha}\left[f\left(L_{t}\right)\right]^{\alpha}\right\}- \\
-\frac{Q_{t+1}^{\alpha}\left(1-L_{t+1}\right)}{\left[f\left(L_{t+1}\right)\right]^{1-\alpha}}\left[1+\omega_{K}\left(Q_{t}, L_{t}\right)\right]=0
\end{gathered}
$$

where

$$
f\left(L_{t}\right)=L_{C, t}=L_{t}-\frac{\beta(1-\mu)}{1-\beta}\left(1-L_{t}\right)
$$

and

$$
\omega_{K}\left(Q_{t}, L_{t}\right)=\frac{K_{t+1}-K_{t}}{K_{t}}=(1-\tau) Q_{t}^{\alpha}\left[f\left(L_{t}\right)\right]^{\alpha}-\frac{\alpha \beta \mu Q_{t}^{\alpha}\left(1-L_{t}\right)}{(1-\beta)\left[f\left(L_{t}\right)\right]^{1-\alpha}}-\delta
$$

An equilibrium path of the economy must also satisfy the transversality condition:

$$
\lim _{t \rightarrow \infty} \theta^{t} \frac{(1-\beta)\left[f\left(L_{t}\right)\right]^{1-\alpha}}{\alpha Q_{t}^{\alpha}\left(1-L_{t}\right)}=0
$$

Along the balanced growth path (BGP) one must have $L_{t+1}=L_{t}=L^{*}, Q_{t+1}=Q_{t}=Q^{*}$ and $Z_{t+1}=Z_{t}=Z^{*}$ in the system (19)-(21), where:

$$
\begin{aligned}
& Q^{*}=q\left(L^{*}\right)=\left[\frac{(1-\delta)(1-\theta)(1-\beta)\left[f\left(L^{*}\right)\right]^{1-\alpha}}{(1-\beta) f\left(L^{*}\right)[(1-\alpha) \theta-1+\tau]+\alpha \beta \mu\left(1-L^{*}\right)}\right]^{1 / \alpha} \\
& Z^{*}=z\left(L^{*}\right)=\left[\frac{\chi+(1+\chi) \omega_{K}\left[q\left(L^{*}\right), L^{*}\right]}{1+\omega_{K}\left[q\left(L^{*}\right), L^{*}\right]}\right] \frac{E_{0}}{\chi q\left(L^{*}\right) L^{*}}
\end{aligned}
$$


and $L^{*}$ is implicitly defined by:

$$
q\left(L^{*}\right)\left[1+\omega_{K}\left[q\left(L^{*}\right), L^{*}\right]\right]=\tau\left[q\left(L^{*}\right) f\left(L^{*}\right)\right]^{\alpha}+(1-\delta) q\left(L^{*}\right)
$$

One can show that, for reasonable parameter values, a BGP characterised by $Q^{*}>0$, $Z^{*}>0, L^{*}>0$ exists. Consider for instance the following numerical example ${ }^{11}$, where $\alpha=0.7, \beta=0.6, \mu=0.5, \tau=0.1, \theta=0.95, \chi=0.2, E_{0}=0.7$ and $\delta=0.0320096$. In this case $Q^{*}=0.724359, Z^{*}=2.2664242, L^{*}=0.59$ and the growth rate of private (and public) stock of capital is $\omega_{K}\left(Q^{*}, L^{*}\right)=0.0134606$. By linearizing the system (19)-(21) around this BGP, one can also show that for the numerical example above $\left(Q^{*}>0, Z^{*}>0\right.$, $\left.L^{*}>0\right)$ is saddle-path stable (see Appendix C).

It is possible to demonstrate that, in order to have a well-defined BGP, $L^{*}$ should be such that:

$$
\bar{L}<L^{*}<\tilde{L}
$$

where

$$
\bar{L}=\frac{\beta(1-\mu)}{1-\beta+\beta(1-\mu)}
$$

\footnotetext{
${ }^{11}$ The values chosen for some parameters - for instance $\alpha, \theta, \delta$ and $\chi$ - are standard in the economic and environmental economic literature. The value for $\beta$ has been chosen to have a slight preference for consumption over leisure, as supported by the average use of time in modern economies (see for instance the American Time Use Survey, available at http://www.bls.gov/tus/). The value for $\mu$ has been chosen so to give equal importance to the bundle $R_{t} C_{t}$ and the consumption of green services $C_{S}$. If the two sectors were to represent the whole manufacturing and service sectors it would be more correct to give $\mu$ a lower value, to reflect the current expenditure shares across sectors. However, $Y_{S}$ represents only a part of the wider service sectors. This, together with the complications caused by the presence of the open-access resource in the welfare function, leads to prefer the more "neutral" approach of attributing the same weight to the two factors. The value chosen for $\tau$ appears to be reasonable and leads to a long-run public expenditure on infrastructure equal to around 5\% of GDP, which is slightly higher but still in line with the values reported by Perée and Välilä (2007) and Felice (2011). Finally, it's worth noticing how the values for the long-run labour supply (59\% of available time) and growth rate $(1.3 \%)$ is very much in line with empirical evidence in high-income countries. See for instance Pissarides (2007).
} 
and

$$
\tilde{L}=\frac{\beta(1-\mu)[(1-\alpha) \theta-1+\tau]-\alpha \beta \mu}{[1-\beta+\beta(1-\mu)][(1-\alpha) \theta-1+\tau]-\alpha \beta \mu}
$$

For values of $L^{*}$ lower than $\bar{L}$ one has that labour supply in the "progressive" sector $f\left(L^{*}\right)$ assumes a negative value, which clearly has no economic meaning. For values of $L^{*}$ higher than $\tilde{L}$ one has that both $Q^{*}$ and $\omega_{K}^{*}$ become complex. Consequently, for the BGP to be well-defined $L^{*}$ must be between $\bar{L}$ and $\tilde{L}$ (see Appendix D).

One can also show that along the BGP the rate of growth of physical capital $\omega_{K}^{*}$ is positive whenever:

$$
L^{*}>L^{\circ}
$$

where

$$
L^{\circ}=\frac{\alpha \beta \mu[\delta+\zeta]+\beta(1-\mu)\{\zeta(1-\tau)-\delta[(1-\alpha) \theta-1+\tau]\}}{\alpha \beta \mu[\delta+\zeta]+[1-\beta+\beta(1-\mu)]\{\zeta(1-\tau)-\delta[(1-\alpha) \theta-1+\tau]\}}
$$

and

$$
\zeta=(1-\delta)(1-\theta)
$$

(see Appendix D for proof). For the numerical example described above, $\bar{L}=0.4285714$, $\tilde{L}=0.6159251$ and $L^{\circ}=0.5863453$.

Along the BGP both types of capital stocks, $K^{*}$ and $K_{G}^{*}$, exhibit the same rate of growth, equal to $\omega_{K}^{*}$. As a result, the ratio between public and private capital $Q^{*}$ remains constant. The employment levels in the two sectors, $L_{C}^{*}$ and $L_{S}^{*}$, also remain stable. The output of the "progressive" sector $Y_{C}^{*}$ grows at the same rate of physical capital. The output of the service sector $Y_{S}^{*}$, on the other hand, exhibits total stagnancy, meaning that the share of physical output of the service sector gradually converges to zero, overshadowed by the ever increasing output of the manufacturing sector. However, it should also be noted 
that along the BGP the relative price of the output of the service sector, $P^{*}$, increases at the same rate of physical capital. Consequently, the nominal value of the output of the service sector also increases at the same rate and its share of aggregate GDP, defined as $G D P=Y_{C}+P Y_{S}$, remains constant in the long-run. Similarly, the shares on total GDP of progressive sector output $Y_{C}$, consumption of the progressive good $C$, investment $I$ and public expenditure in infrastructure $G$; are all constant along the BGP. This can be seen by looking at the equations defining them, which are a function of the sole labour supply $L$ :

$$
\begin{aligned}
& \left(\frac{Y_{C}}{G D P}\right)^{*}=\frac{f\left(L^{*}\right)}{\alpha L^{*}+(1-\alpha) f\left(L^{*}\right)} \\
& \left(\frac{C}{G D P}\right)^{*}=\frac{\alpha \beta \mu\left(1-L^{*}\right)}{(1-\beta)\left[\alpha L^{*}+(1-\alpha) f\left(L^{*}\right)\right]} \\
& \left(\frac{I}{G D P}\right)^{*}=\frac{(1-\tau)(1-\beta) f\left(L^{*}\right)-\alpha \beta \mu\left(1-L^{*}\right)}{(1-\beta)\left[\alpha L^{*}+(1-\alpha) f\left(L^{*}\right)\right]} \\
& \left(\frac{G}{G D P}\right)^{*}=\frac{\tau f\left(L^{*}\right)}{\alpha L^{*}+(1-\alpha) f\left(L^{*}\right)}
\end{aligned}
$$

For the numerical example provided, $\left(\frac{Y_{C}}{G D P}\right)^{*}=0.5675540,\left(\frac{C}{G D P}\right)^{*}=0.4324460$, $\left(\frac{I}{G D P}\right)^{*}=0.0783526$ and $\left(\frac{G}{G D P}\right)^{*}=0.0567554$.

It can also be shown that along the BGP the common resource $R$ grows at a rate $\omega_{R}^{*}=-\frac{\omega_{K}^{*}}{1+\omega_{K}^{*}}$ (for the numerical example presented above $\omega_{R}^{*}=-0.0132818$ ). In other words, whenever physical capital grows at a positive long-run growth rate the common resource asymptotically converges to zero. The depletion of $R$, an externality produced by the output of the "progressive" sector, is balanced by the increase in the consumption of such output, which grows at a rate equal to $\omega_{K}^{*}$. The substitution process that takes place between private consumption of the "progressive" good and the common resource along the BGP, together with the constant consumption of the "stagnant" good and the constant 
amount of labour supply provided, generates a constant value of long-run utility $U^{*}$, equal to:

$$
U^{*}=\beta \ln \left\{\left[\frac{\alpha \beta \mu Q^{*} Z^{*}\left(1-L^{*}\right)}{(1-\beta)\left[f\left(L^{*}\right)\right]^{1-\alpha}}\right]^{\mu}\left[\frac{\beta(1-\mu)\left(1-L^{*}\right)}{1-\beta}\right]^{(1-\mu)}\right\}+(1-\beta) \ln \left(1-L^{*}\right)
$$

\section{Transitional dynamics: a numerical example}

In the previous section I have showed that, for reasonable parameter values, a BGP with a positive long-run growth rate exists and is saddle-path stable. However, it has not been possible to discuss the features of the structural change to green services. This is due to the fact that, by definition, sectoral employment shares are constant along the BGP. It is therefore necessary to study the transition of the system to the BGP, along which the allocation of labour across sectors is allowed to change.

In order to do so, the system is linearized around $\left(Q^{*}, Z^{*}, L^{*}\right)$. The unique path converging to the BGP is governed by:

$$
\begin{aligned}
& Q_{t}-Q^{*}=D_{1} c_{11} \lambda_{1}^{t}+D_{2} c_{12} \lambda_{2}^{t} \\
& Z_{t}-Z^{*}=D_{1} c_{21} \lambda_{1}^{t}+D_{2} c_{22} \lambda_{2}^{t} \\
& L_{t}-L^{*}=D_{1} c_{31} \lambda_{1}^{t}+D_{2} c_{32} \lambda_{2}^{t}
\end{aligned}
$$

where

$$
\left[\begin{array}{l}
c_{11} \\
c_{12} \\
c_{13}
\end{array}\right]=\left[\begin{array}{l}
0 \\
1 \\
0
\end{array}\right] \text { and }\left[\begin{array}{l}
c_{21} \\
c_{22} \\
c_{23}
\end{array}\right]=\left[\begin{array}{c}
-0.3023314 \\
1 \\
-0.0551214
\end{array}\right]
$$

are the characteristic vectors associated with, respectively, $\lambda_{1}$ and $\lambda_{2}$; and $D_{1}$ and $D_{2}$ are constants whose values are to be determined. 
The features of the reallocation of labour across the two sectors that takes place along the transition to the BGP are determined by the initial value of the public-to-private capital ratio $Q$. In particular, there is a shift of labour towards the green service sector whenever $Q_{0}$ is higher than its BGP value $Q^{*}$, and a shift in the opposite direction whenever $Q_{0}<Q^{*}$ (see Appendix E). Structural change in this model is thus driven by the difference in productivity across the two sectors.

Figure 4 displays the dynamics of a selection of variables in the two alternative scenarios. In the first one $Q_{0}=0.8>Q^{*}$, while in the second one $Q_{0}=0.65<Q^{*}$. $Z_{0}$ is set equal to its BGP value in both scenarios. The charts show that any time $Q_{0}>Q^{*}$ $\left(Q_{0}<Q^{*}\right)$ the initial labour supply is higher (lower), the share of employment in the green service sector is lower (higher) and the rate of growth of capital is higher (lower) than their long-run values. Welfare starts off with a lower (higher) value than the long-run one, then overshoots (undershoots) it and subsequently converges to it. This dynamics is due to the fact that, before converging to its BGP value, the rate of growth of capital is higher (lower) than what it would be needed to perfectly compensate the growth of $R$ of opposite sign and keep $Z$ constant. In other words, even if its initial value is set to be equal to the long-run one, $Z$ moves along the transition, increasing (decreasing) and gradually converging back to the starting point.

The structural change to green services is thus characterized by having a very high initial gap between private and public capital growth rates (Figure 5). The share of GDP devoted to private investment is high. As a consequence, the system grows quite strongly driven by its manufacturing sector and labour supply is higher than its long-run value. However, as the public-to-private capital ratio $\left(Q^{*}\right)$ decreases, so does the marginal productivity of private capital, making it less profitable to invest. The investment share of GDP declines, with a higher proportion of output being consumed (Figure 5b), and the 
Figure 4: Transitional dynamics (solid lines: $Q_{0}>Q^{*}$; dotted lines: $Q_{0}<Q^{*}$ )

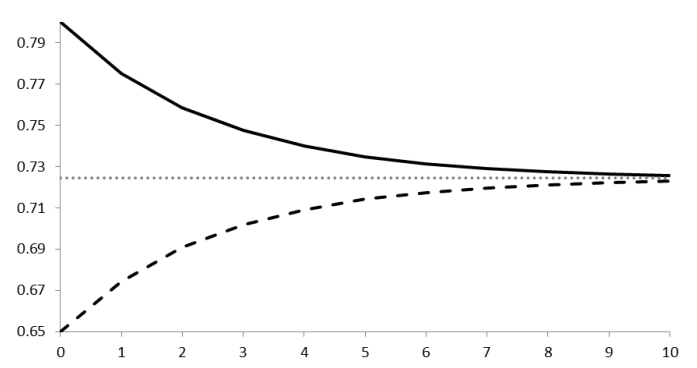

(a) Public-to-private capital ratio

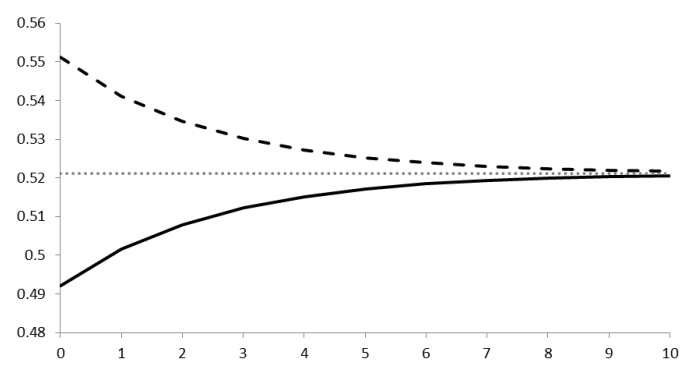

(c) Share of employment in services

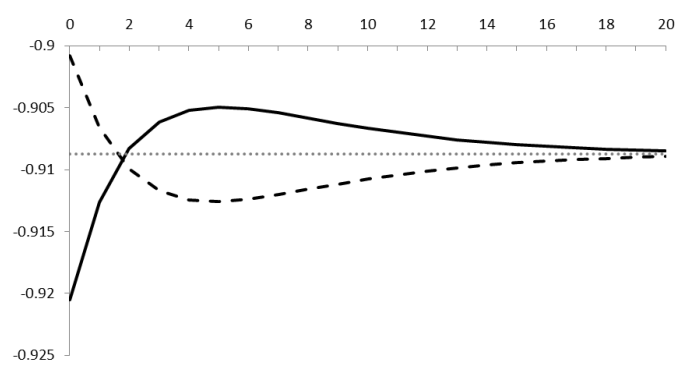

(e) Utility

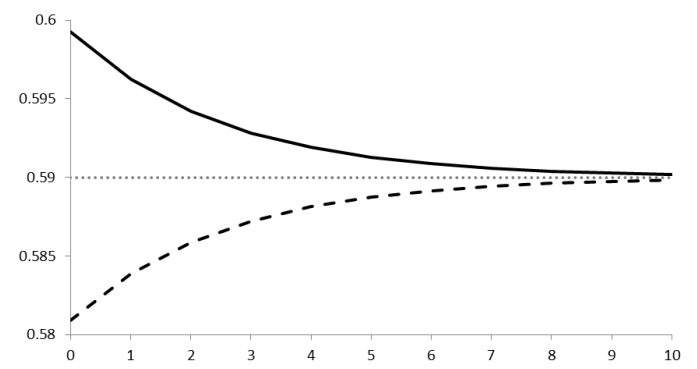

(b) Total labour supply

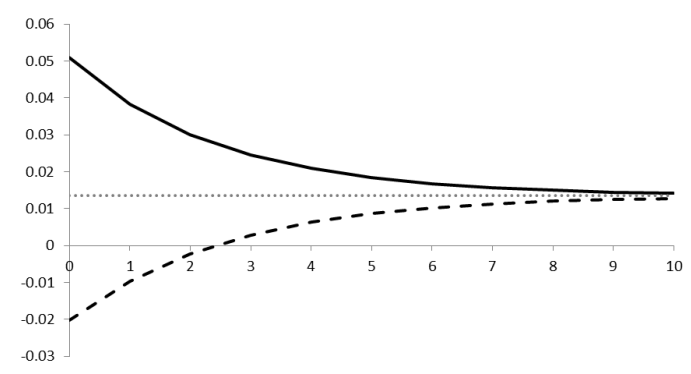

(d) Private capital growth rate

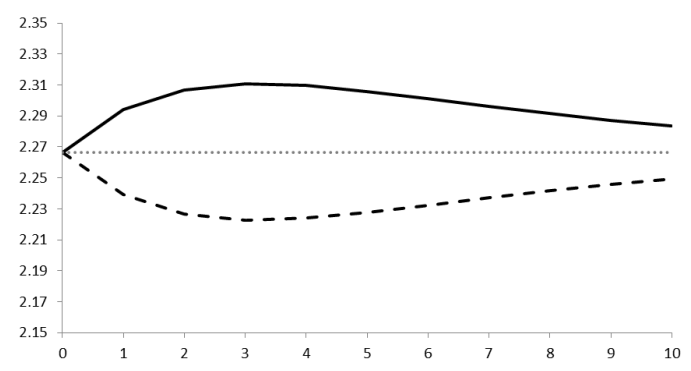

(f) $Z \equiv R K$

growth rate of private capital gradually converges to its BGP value, which is equal to the BGP growth rate of public capital.

The open-access asset $R$ gets depleted quite quickly at the beginning, but as growth 
Figure 5: Growth rates and output shares in the "green" structural change case

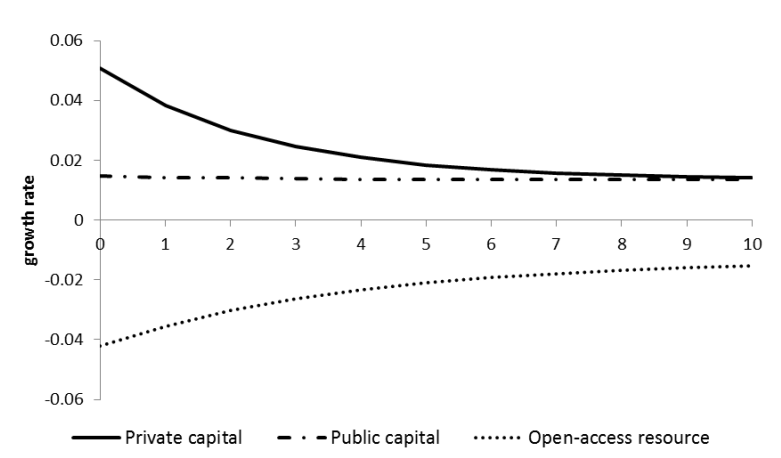

(a) Growth rates

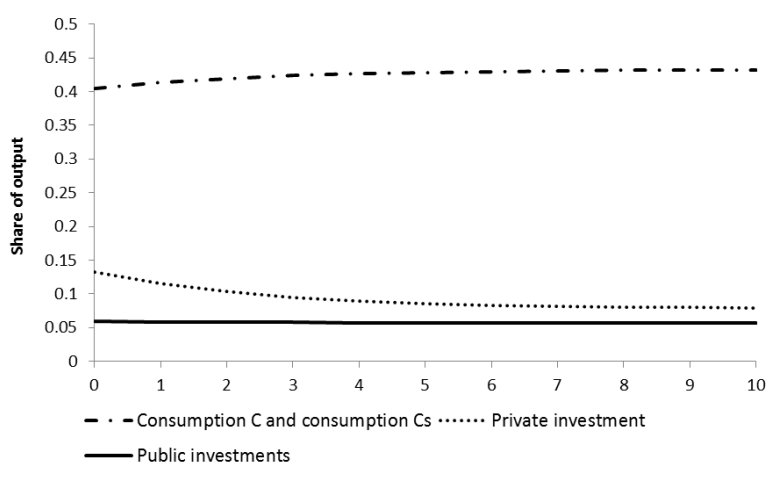

(b) Output shares

slows down the depletion rate adjusts to its BGP value. In the long-run, $R$ converges asymptotically to zero. The substitution process between $R$ and $C$ makes welfare converge to a constant value.

\section{Long run effects of a change in some relevant parameters}

\subsection{Long run effects of a change in $\tau$}

I now consider a marginal increase in $\tau$, i.e. the fraction of the output of the progressive sector that the government employs in the creation of public capital. The aim of the exercise is to study the effect of such a change on the long-run rate of growth and the long-run level of welfare, as these may be in conflict with each other.

Using the equation that defines the dynamics of private capital and (21) one can find that:

$$
l(Q, L, \tau, \mu)=[Q f(L)]^{\alpha}\left[\theta(1-\alpha)-1+\tau+\frac{\alpha \beta \mu(1-L)}{(1-\beta) f(L)}\right]-(1-\delta)(1-\theta)=0
$$


Using the implicit function theorem it is possible to compute that for the numerical example presented above:

$$
\left.\frac{\partial L}{\partial \tau}\right|_{L=L^{*}}=-\left.\frac{\left.\frac{\partial l(Q, L, \tau, \mu)}{\partial \tau}\right|_{L=L^{*}}}{\frac{\partial l(Q, L, \tau, \mu)}{\partial L}}\right|_{L=L^{*}} 0
$$

meaning that an increase in tax rate $\tau$ produces an increase in total labour supply. The expansion of public infrastructure investment, financed by tax revenues, improves the profitability of the manufacturing sector, which produces more and thus employs more labour. This will produce three effects on households' utility: a) higher production is transformed in higher consumption, increasing welfare; b) higher production produces negative externalities on $R$, decreasing welfare; c) working hours are higher, decreasing welfare. Alternatively, looking at (38), it is possible to see that the effect of a change in $\tau$ on utility is a combination of the effects of a change in $\tau$ on $Q, Z$ and $L$. It's not straightforward to anticipate which of these effects will predominate.

For our numerical example, using (43) one can find the marginal effect of an increase in $\tau$ on the BGP values of all the other variables. In particular, one can show that $\left.\frac{\partial f(L)}{\partial \tau}\right|_{f(L)=f\left(L^{*}\right)}>0,\left.\frac{\partial Q}{\partial \tau}\right|_{Q=Q^{*}}>0,\left.\frac{\partial Z}{\partial \tau}\right|_{Z=Z^{*}}<0$ and $\left.\frac{\partial \omega_{K}}{\partial \tau}\right|_{\omega_{K}=\omega_{K}^{*}}>0$. Finally it is possible to show that $\left.\frac{\partial U}{\partial \tau}\right|_{U=U^{*}}<0^{12}$.

In other words, a permanent increase in the tax rate $\tau$ - and thus in the proportion of output devoted to the creation of infrastructure - has a positive impact on the public-toprivate capital ratio $Q$ and on the economy long-run rate of growth $\omega_{K}$, as suggested by the literature (see section 2.3). However, the negative effect on utility of the increase in

\footnotetext{
${ }^{12}$ More precisely, $\left.\frac{\partial L}{\partial \tau}\right|_{L=L^{*}}=0.275629,\left.\frac{\partial f(L)}{\partial \tau}\right|_{f(L)=f\left(L^{*}\right)}=0.4476723,\left.\frac{\partial Q}{\partial \tau}\right|_{Q=Q^{*}}=3.6607212,\left.\frac{\partial Z}{\partial \tau}\right|_{Z=Z^{*}}=$ $-\left.6.1065927 \frac{\partial \omega_{K}}{\partial \tau}\right|_{\omega_{K}=\omega_{K}^{*}}=0.4362026$ and $\left.\frac{\partial U}{\partial \tau}\right|_{U=U^{*}}=-0.0587450$.
} 
working hours and the accelerated degradation of the environmental stock predominates, thus leading to a reduction in the long-run level of welfare.

By differentiating equation (23) with respect to the tax rate, it is also possible to identify the value of $\tau$ that maximizes long-run growth, which is equal to:

$$
\tau_{M A X}=\frac{\alpha(1-\alpha \xi) \epsilon_{Q}+[\alpha(1-\xi)+\xi] \epsilon_{f}+\xi \epsilon_{L}}{1+\alpha\left(\epsilon_{Q}+\epsilon_{f}\right)}
$$

where

$$
\xi=\frac{\alpha \beta \mu(1-L)}{(1-\beta) f(L))}
$$

and $\epsilon_{Q}, \epsilon_{f}$ and $\epsilon_{L}$ represent the elasticity of the public-to-private capital ratio, the labour supply in the progressive sector and total labour supply, respectively, with respect to a change in $\tau$.

\subsection{Long run effects of a change in $\mu$}

I now investigate the effects of a marginal change in $\mu$, i.e. the parameter that determines the relative importance of the "progressive" good with respect to green services in generating utility for the households. Interpreting equation (2) as a household production function á la Becker, a change in $\mu$ affects the relative efficiency with which the inputs $\left(R_{t}, C_{t}\right.$ and $\left.C_{S, t}\right)$ contribute to the production of $X_{t}$. For instance, an increase in $\mu$ can capture a technological change making the manufactured goods relatively more efficient in satisfying consumers needs and desires.

By adopting the same steps used in section 6.1 it is possible to show that $\left.\frac{\partial L}{\partial \mu}\right|_{L=L^{*}}>0$, $\left.\frac{\partial f(L)}{\partial \tau}\right|_{f(L)=f\left(L^{*}\right)}>0,\left.\frac{\partial Q}{\partial \tau}\right|_{Q=Q^{*}}<0,\left.\frac{\partial Z}{\partial \tau}\right|_{Z=Z^{*}}>0,\left.\frac{\partial \omega_{K}}{\partial \mu}\right|_{\omega_{K}=\omega_{K}^{*}}>0$ and $\left.\frac{\partial U}{\partial \mu}\right|_{U=U^{*}}<0^{13}$

\footnotetext{
${ }^{13}$ More precisely, $\left.\frac{\partial L}{\partial \mu}\right|_{L=L^{*}}=0.2452635,\left.\quad \frac{\partial f(L)}{\partial \tau}\right|_{f(L)=f\left(L^{*}\right)}=0.4292111,\left.\quad \frac{\partial Q}{\partial \tau}\right|_{Q=Q^{*}}=-0.4698933$, $\left.\frac{\partial Z}{\partial \tau}\right|_{Z=Z^{*}} 0.8631288,\left.\frac{\partial \omega_{K}}{\partial \mu}\right|_{\omega_{K}=\omega_{K}^{*}}=0.0572080$ and $\left.\frac{\partial U}{\partial \mu}\right|_{U=U^{*}}=-0.8153043$.
} 
What happens in this case is that a marginal rise in $\mu$ expands the relative importance of both the consumption of the manufactured good $C$ and the open-access stock $R$, to the detriment of consumption of green services $C_{S}$. Production in the manufacturing sector increases, together with the labour employed. The long-run growth rate $\omega_{K}$ is now higher. Unlike the previous example using $\tau$, an increase in $\mu$ produces a negative effect on the public-to-private capital ratio $Q$. This is due to the fact that private capital expands - as a result of higher demand of "progressive" goods - while the proportion of output flowing to public investment remains unchanged. Considering that the rise in $L$ also has a negative effect on welfare, as defined by (38), the increase in $Z$ is in this case the only factor impacting utility positively, but this is insufficient to overcome the other two negative effects.

As before, a conflict between the long-run growth rate and the long-run level of welfare can arise. There are no direct policy implications in this case, but the exercise is still interesting as it grasps the effect of a change in preferences and consumption habits.

\section{Conclusions}

Despite the fact that most of the discussion around the transition to a low-carbon society has been focusing on the ways to decarbonise the most polluting sectors, e.g. through the implementation of a carbon tax, the expansion of the share of economic activity taking place in non-polluting sectors - a "green" structural change - is an equally crucial element of the process. I have argued that the category of "green" services shouldn't include only the activities explictly oriented to decarbonisation - for instance, production of clean energy - but also those that by nature have a low impact on ecological resources, even if they don't contribute to make other sectors more environmentally sustainable. Examples of this latter form of green services include sports, culture, arts, education, health, social work, membership organizations, and others. 
As it has been discussed in Section 2, these activities typically exhibit a very low productivity growth rate, due to the non-substitutability of human participation in their production process. Green services in this paper are thus meant to represent a class of goods and services characterised by high intensity of labour and dedication, reduced consumption of material resources, low polluting emissions and a strong attachment to the local milieu.

After having shown that a relative expansion of these sectors is indeed taking place, I have investigated its features by means of a growth model with two sectors - a "progressive" manufacturing one and a "stagnant" service one - having: a) a different capability of achieving increases in labour productivity; b) a different impact on an open-access resource representing environmental quality, whose stock enters as an argument in the households' welfare function. The role of public capital is crucial here as it creates the conditions for a rise in labour productivity in the manufacturing sector, and thus produces the sectoral productivity differential that eventually drives structural change.

Along the Balanced Growth Path, the economy grows at a constant rate. Private capital, public capital, output of the manufacturing sector and consumption of its output all grow at the same rate. The output of the service sector, on the other hand, doesn't grow at all. This makes the share of physical output of the service sector gradually converges to zero. However, since the relative price of services also increases at the same rate as the economy, the nominal value of the output of the service sector also expands at the same rate and its share of aggregate GDP remains constant in the long-run. It is also shown that in the long-run the common resource asymptotically converges to zero because of the externality produced by the manufacturing sector. A substitution process thus takes place between private consumption of the "progressive" good and the common resource along the BGP. This leads welfare to reach a steady level in the long-run, despite the fact that the economy is growing. 
Since along the BGP employment shares are by definition constant and no structural change is possible, I have studied the transitional dynamics of the system, where employment shares are allowed to change. I have showed that a structural change towards green services occurs any time the initial value of the public-to-private capital ratio is above its BGP value. Using numerical examples I have provided a characterisation of the dynamics.

Finally, I have used the same numerical example to investigate the long-run effects of a change in some relevant parameters. A marginal increase in the investment in public capital generates a positive effect on long-run growth, as expected, but simultaneously affects negatively the level of welfare. This happens because, despite consumption has increased, both the environmental asset and leisure time have gone down. Similarly, an increase in the technological parameter entering the household production function, that can be interpreted as an improvement in the relative efficiency of material goods in generating consumption services (for instance, through an increase in the technological content embodied in private market goods) boosts the long-run growth rate but simultaneously depresses households' welfare level. 


\section{A. Tables}

Table 1: Contribution of selected sectors to UK energy use ${ }^{14}$

\begin{tabular}{|l|cccccccc|}
\hline Sector & $\mathbf{2 0 0 4}$ & $\mathbf{2 0 0 5}$ & $\mathbf{2 0 0 6}$ & $\mathbf{2 0 0 7}$ & $\mathbf{2 0 0 8}$ & $\mathbf{2 0 0 9}$ & $\mathbf{2 0 1 0}$ & $\mathbf{2 0 1 1}$ \\
\hline Agriculture, forestry and fishing & 1.0 & 1.0 & 0.9 & 1.0 & 1.0 & 1.0 & 1.1 & 1.1 \\
\hline Manufacturing & 19.0 & 18.8 & 18.8 & 18.9 & 19.0 & 17.8 & 17.5 & 18.8 \\
\hline $\begin{array}{l}\text { Energy, gas, steam \& air conditioning, wa- } \\
\text { ter supply, sewerage, waste management } \\
\text { activities \& remediation services }\end{array}$ & 22.3 & 22.6 & 23.5 & 22.8 & 22.4 & 23.1 & 22.5 & 23.0 \\
\hline Construction & 1.5 & 1.6 & 1.6 & 1.7 & 1.7 & 1.6 & 1.5 & 1.6 \\
\hline $\begin{array}{l}\text { Transport and storage; information and } \\
\text { communication }\end{array}$ & 13.9 & 14.5 & 13.8 & 14.3 & 14.2 & 14.0 & 13.8 & 15.1 \\
\hline Accommodation and food services & 0.8 & 0.8 & 0.8 & 0.8 & 0.8 & 0.8 & 0.8 & 0.8 \\
\hline $\begin{array}{l}\text { Public administration \& defence; compul- } \\
\text { sory social security }\end{array}$ & 1.7 & 1.5 & 1.5 & 1.5 & 1.5 & 1.4 & 1.3 & 1.3 \\
\hline Education & 0.7 & 0.8 & 0.7 & 0.8 & 0.7 & 0.7 & 0.7 & 0.7 \\
\hline Human health \& social work activities & 1.1 & 1.2 & 1.2 & 1.1 & 1.2 & 1.1 & 1.2 & 1.1 \\
\hline $\begin{array}{l}\text { Arts, entertainment and recreation; other } \\
\text { service activities }\end{array}$ & 0.6 & 0.7 & 0.7 & 0.7 & 0.7 & 0.8 & 0.8 & 0.8 \\
\hline
\end{tabular}

Table 2: Contribution of selected sectors to UK greenhouse gases emissions ${ }^{15}$

\begin{tabular}{|l|cccccccc|}
\hline Sector & $\mathbf{2 0 0 4}$ & $\mathbf{2 0 0 5}$ & $\mathbf{2 0 0 6}$ & $\mathbf{2 0 0 7}$ & $\mathbf{2 0 0 8}$ & $\mathbf{2 0 0 9}$ & $\mathbf{2 0 1 0}$ & $\mathbf{2 0 1 1}$ \\
\hline Agriculture, forestry and fishing & 7.7 & 7.7 & 7.6 & 7.4 & 7.5 & 8.0 & 7.9 & 8.4 \\
\hline Manufacturing & 16.6 & 16.3 & 16.0 & 16.2 & 16.0 & 14.9 & 14.6 & 15.4 \\
\hline $\begin{array}{l}\text { Energy, gas, steam \& air conditioning, wa- } \\
\text { ter supply, sewerage, waste management } \\
\text { activities \& remediation services }\end{array}$ & 28.9 & 29.2 & 30.7 & 30.4 & 30.2 & 29.3 & 29.4 & 29.0 \\
\hline Construction & 1.5 & 1.5 & 1.5 & 1.6 & 1.6 & 1.6 & 1.5 & 1.6 \\
\hline $\begin{array}{l}\text { Transport and storage; information and } \\
\text { communication }\end{array}$ & 13.2 & 13.8 & 13.0 & 13.3 & 13.4 & 13.4 & 13.1 & 14.4 \\
\hline Accommodation and food services & 0.5 & 0.5 & 0.4 & 0.4 & 0.5 & 0.5 & 0.5 & 0.5 \\
\hline $\begin{array}{l}\text { Public administration \& defence; compul- } \\
\text { sory social security }\end{array}$ & 1.3 & 1.1 & 1.1 & 1.1 & 1.1 & 1.1 & 1.0 & 1.0 \\
\hline Education & 0.5 & 0.6 & 0.6 & 0.6 & 0.6 & 0.5 & 0.5 & 0.5 \\
\hline Human health \& social work activities & 0.7 & 0.8 & 0.7 & 0.7 & 0.8 & 0.8 & 0.8 & 0.7 \\
\hline $\begin{array}{l}\text { Arts, entertainment and recreation; other } \\
\text { service activities }\end{array}$ & 0.4 & 0.4 & 0.4 & 0.4 & 0.4 & 0.4 & 0.4 & 0.4 \\
\hline
\end{tabular}

\footnotetext{
${ }^{14}$ Million tonnes of oil equivalent. Includes electricity. Source: ONS (2013)
} 


\section{B. Derivation of the system (19)-(21)}

The problem of the representative household can be solved by maximising

$$
\begin{aligned}
\sum_{t=0}^{\infty} \theta^{t}\left\{\beta \ln \left[\left(R_{t} C_{t}\right)^{\mu} C_{S, t}^{1-\mu}\right]+(1-\beta) \ln \left(1-L_{t}\right)+\right. \\
\left.\quad+\lambda_{t}\left[w_{t} L_{t}+r_{t} K_{t}+\pi_{t}+(1-\delta) K_{t}-C_{t}-P_{t} C_{S, t}-K_{t+1}-T_{t}\right]\right\}
\end{aligned}
$$

with respect to $C_{t}, C_{S, t}, L_{t}, K_{t+1}$ and $\lambda_{t}$, where $\lambda_{t}$ is a lagrangian multiplier, thus obtaining

$$
\begin{aligned}
& \frac{\beta \mu}{C_{t}}=\lambda_{t} \\
& \frac{\beta(1-\mu)}{C_{S, t}}=\lambda_{t} P_{t} \\
& \lambda_{t}=\lambda_{t+1} \theta\left(1-\delta+r_{t}\right) \\
& \frac{1-\beta}{1-L_{t}}=\lambda_{t} w_{t}
\end{aligned}
$$

and the budget constraint.

A transversality condition must also be respected in equilibrium:

$$
\lim _{t \rightarrow \infty} \theta^{t} \lambda_{t} K_{t}=0
$$

Using (Appendix B.2), (Appendix B.5) and (17) one can find an expression for $C_{t}$ :

$$
C_{t}=\frac{\alpha \beta \mu Q_{t}^{\alpha} K_{t}\left(1-L_{t}\right)}{(1-\beta) L_{C, t}^{1-\alpha}}
$$

\footnotetext{
${ }^{15}$ Thousand tonnes of $\mathrm{CO} 2$ equivalent. Greenhouse gases include: $\mathrm{CO} 2, \mathrm{CH} 4, \mathrm{~N} 2 \mathrm{O}, \mathrm{HFC}$, PFCs and SF6. Source: ONS (2013)
} 
Using (Appendix B.2), (Appendix B.3), (8), (18) and (Appendix B.7) it is possible to find (22).

Substituting equations (6), (Appendix B.7) and (22) into the dynamics of private capital allows to obtain (23).

Using equations (Appendix B.2), (17), (Appendix B.7), (23) and (22) one can rewrite (Appendix B.4) as 19.

From the dynamics of public capital (10) is then possible to obtain (20).

Finally, using (6), the dynamics of the common resource (12) can be written as (21)

\section{Stability of the BGP}

In order to analyse the stability of system (19)-(21) one can linearize it around $\left(Q^{*}>0\right.$, $\left.Z^{*}>0, L^{*}>0\right)$ :

$$
\left[\begin{array}{c}
Q_{t+1}-Q^{*} \\
Z_{t+1}-Z^{*} \\
L_{t+1}-L^{*}
\end{array}\right]=\left[\begin{array}{lll}
a_{11} & a_{12} & a_{13} \\
a_{21} & a_{22} & a_{23} \\
a_{31} & a_{32} & a_{33}
\end{array}\right]\left[\begin{array}{l}
Q_{t}-Q^{*} \\
Z_{t}-Z^{*} \\
L_{t}-L^{*}
\end{array}\right]
$$

where

$$
\begin{array}{ccc}
a_{11}=-\frac{\Phi_{Q_{t}}}{\Phi_{Q_{t}+1}} & a_{12}=0 & a_{13}=-\frac{\Phi_{L_{t}}}{\Phi_{Q_{t}+1}} \\
a_{21}=-\frac{\Lambda_{Q_{t}}}{\Lambda_{Z_{t+1}}} \Phi_{22}=-\frac{\Lambda_{Z_{t}}}{\Lambda_{Z_{t+1}}} & a_{23}=-\frac{\Lambda_{L_{t}}}{\Lambda_{Z_{t}+1}} \\
a_{31}=-\frac{\Psi_{Q_{t}}}{\Psi_{L_{t+1}}}+\frac{\Psi_{Q_{t+1}}}{\Psi_{L_{t+1}} \Phi_{Q_{t+1}}} & a_{32}=0 & a_{33}=-\frac{\Psi_{L_{t}}}{\Psi_{L_{t+1}}}+\frac{\Psi_{Q_{t+1}}}{\Psi_{L_{t+1}} \Phi_{Q_{t+1}}}
\end{array}
$$

and:

$$
\begin{aligned}
& \Phi_{Q t+1}=1+\omega_{K}\left(Q_{t}, L_{t}\right) \\
& \Phi_{Q_{t}}=Q_{t+1} \omega_{K, Q_{t}}\left(Q_{t}, L_{t}\right)-\alpha \tau Q_{t}^{\alpha-1}\left[f\left(L_{t}\right)\right]^{\alpha}-1+\delta \\
& \Phi_{L_{t}}=Q_{t+1} \omega_{K, L_{t}}\left(Q_{t}, L_{t}\right)-\alpha \tau Q_{t}^{\alpha}\left[f\left(L_{t}\right)\right]^{\alpha-1} f_{L_{t}}\left(L_{t}\right)
\end{aligned}
$$




$$
\begin{gathered}
\Lambda_{Z_{t+1}}=\frac{1}{1+\omega_{K}\left(Q_{t}, L_{t}\right)} \\
\Lambda_{Q_{t}}=-\frac{Z_{t+1} \omega_{K, Q_{t}}\left(Q_{t}, L_{t}\right)}{\left[1+\omega_{K}\left(Q_{t}, L_{t}\right)\right]^{2}}+\alpha \chi \frac{Z_{t}^{2} Q_{t}^{\alpha-1}\left[f\left(L_{t}\right)\right]^{\alpha}}{E 0} \\
\Lambda_{Z_{t}}=2 \chi \frac{Z_{t}\left[Q_{t} f(L)_{t}\right]^{\alpha}}{E_{0}}-1-\chi \\
\Lambda_{L_{t}}=-\frac{Z_{t+1} \omega_{K, L_{t}}\left(Q_{t}, L_{t}\right)}{\left[1+\omega_{K}\left(Q_{t}, L_{t}\right)\right]^{2}}+\alpha \chi \frac{Z_{t}^{2} Q_{t}^{\alpha}\left[f\left(L_{t}\right)\right]^{\alpha-1}}{E 0} \\
\Psi_{Q_{t+1}}=-\frac{\alpha Q_{t+1}^{\alpha-1}\left(1-L_{t+1}\right)}{\left[f\left(L_{t+1}\right)\right]^{1-\alpha}}\left[1+\omega_{K}\left(Q_{t}, L_{t}\right)\right] \\
\Psi_{L_{t+1}}=\left[1+\omega_{K}\left(Q_{t}, L_{t}\right)\right] Q_{t+1}^{\alpha}\left\{(\alpha-1)\left(1-L_{t}\right)\left[f\left(L_{t+1}\right)\right]^{\alpha-2}\right. \\
\left.f_{L_{t+1}}\left(L_{t}+1\right)-f\left(L_{t+1}\right)^{\alpha-1}\right\} \\
\Psi_{Q_{t}=} \begin{array}{c}
\alpha \theta(1-\delta) \frac{Q_{t}^{\alpha-1}\left(1-L_{t}\right)}{\left[f\left(L_{t}\right)\right]^{1-\alpha}}+2 \alpha \theta(1-\alpha)\left(1-L_{t}\right)\left[Q_{t} f\left(L_{t}\right)\right]^{2 \alpha-1}- \\
\Psi_{L_{t}}=\theta(1-\delta) Q_{t}^{\alpha}\left\{(\alpha-1)\left(1-L_{t}\right)\left[f\left(L_{t}\right)\right]^{\alpha-2} f_{L_{t}}\left(L_{t}\right)-f\left(L_{t}\right)^{\alpha-1}\right\}+ \\
+\theta(1-\alpha) Q_{t}^{2 \alpha}\left\{(2 \alpha-1)\left(1-L_{t}\right)\left[f\left(L_{t}\right)\right]^{2 \alpha-2} f_{L_{t}}\left(L_{t}\right)-f\left(L_{t}\right)^{2 \alpha-1}\right\}- \\
-\frac{Q_{t+1}^{\alpha}\left(1-L_{t+1}\right) \omega_{K, L_{t}}\left(Q_{t}, L_{t}\right)}{\left[f\left(L_{t+1}\right)\right]^{1-\alpha}}
\end{array}
\end{gathered}
$$

where:

$$
\begin{aligned}
& f_{L_{t}}=f_{L_{t+1}}=1+\frac{\beta(1-\mu)}{1-\beta} \\
& \omega_{K, Q_{t}}\left(Q_{t}, L_{t}\right)=\alpha(1-\tau) Q_{t}^{\alpha-1}\left[f\left(L_{t}\right)\right]^{\alpha}-\frac{\alpha^{2} \beta \mu Q_{t}^{\alpha-1}\left(1-L_{t}\right)}{(1-\beta)\left[f\left(L_{t}\right)\right]^{1-\alpha}}
\end{aligned}
$$




$$
\begin{aligned}
\omega_{K, L_{t}}\left(Q_{t}, L_{t}\right)=\alpha(1-\tau) Q_{t}^{\alpha}\left[f\left(L_{t}\right)\right]^{\alpha-1} f_{L_{t}}\left(L_{t}\right)- \\
\quad-\frac{\alpha \beta \mu Q_{t}^{\alpha}}{1-\beta}\left[(\alpha-1)\left(1-L_{t}\right)\left[f\left(L_{t}\right)\right]^{\alpha-2} f_{L_{t}}\left(L_{t}\right)-\left[f\left(L_{t}\right)\right]^{\alpha-1}\right]
\end{aligned}
$$

and all derivatives must be evaluated at $\left(Q^{*}>0, Z^{*}>0, L^{*}>0\right)$. The characteristic equation of the system is:

$$
\lambda^{3}-\operatorname{tr}(A) \lambda^{2}+\mathrm{m}(A) \lambda-\operatorname{det}(A)
$$

where $\operatorname{tr}(A), \mathrm{c}(A)$ and $\operatorname{det}(A)$ are, respectively, the trace, the sum of the principal minors and the determinant of matrix $A$. The solutions $\lambda_{1}, \lambda_{2}$ and $\lambda_{3}$ are the eigenvalues of $A$.

Consider the following numerical example, where $\alpha=0.7, \beta=0.6, \mu=0.5, \tau=$ $0.1, \theta=0.95, \chi=0.2, E_{0}=0.7$ and $\delta=0.0320096$. In this case $Q^{*}=0.724359$, $Z^{*}=2.2664242, L^{*}=0.59$ and the growth rate of private (and public) stock of capital is $\omega_{K}\left(Q^{*}, L^{*}\right)=0.0134606$. The values of the roots of the characteristic equation $\left(\lambda_{1}=\right.$ $0.7838473, \lambda_{2}=0.6727845$ and $\lambda_{3}=-1.5152008$ ) imply that the system is saddle-path stable.

\section{Proof of conditions (28) and (31)}

From equation (22) it's easy to see that $f\left(L^{*}\right)=0$ whenever $L^{*}<\bar{L}=\frac{\beta(1-\mu)}{1-\beta+\beta(1-\mu)}$. From equation (25) it can be shown that $Q^{*}$ assumes a complex value anytime the expression inside the square brackets assumes a negative value. Once we rule out the case for which $L^{*}<\bar{L}$, we can conclude that the numerator of the expression is always positive. Hence $Q^{*}$ is a complex number whenever the denominator of the ratio is lower than zero, that is $L^{*}<\tilde{L}$.

One can also prove condition (31) by substituting the BGP value for $Q *$ and $f\left(L^{*}\right)$, equations (25) and (22) respectively, into the expression for $\omega_{K}^{*}$ in (23). 


\section{E. Discussion of initial values}

For $\mathrm{t}=0$ system (39)-(41) becomes:

$$
\begin{aligned}
& Q_{0}-Q^{*}=D_{1} c_{11}+D_{2} c_{12} \\
& Z_{0}-Z^{*}=D_{1}+D_{2} \\
& L_{0}-L^{*}=D_{1} c_{31}+D_{2} c_{32}
\end{aligned}
$$

Solving the system for $D_{1}, D_{2}, L_{0}$ gives:

$$
\begin{aligned}
& D_{2}=\frac{Q_{0}-Q^{*}-\left(Z_{0}-Z^{*}\right) c_{11}}{c_{12}-c_{11}} \\
& D_{1}=Z_{0}-Z^{*}-D_{2} \\
& L_{0}=D_{1} c_{31}+D_{2} c_{32}+L^{*}
\end{aligned}
$$

To have a increasing share of employment in the green service sector during the tran-

sition to the BGP one must have $\frac{f\left(L_{0}\right)}{L_{0}}>\frac{f\left(L^{*}\right)}{L^{*}}$. By substituting (Appendix E.4), (Appendix E.5) and (Appendix E.6) into (22), it is possible to show that this is satisfied only if $Q_{0}>Q^{*}$. 


\section{References}

Acheson, J., 2011. Multi-factor productivity: estimates for 1970 to 2009. Economic \& Labour Market Review May 2011.

Agenor, P., 2010. A theory of infrastructure-led development. Journal of Economic Dynamics and Control 34, 932-950.

Barro, R., Sala-i-Martin, X., 1994. Economic Growth. McGraw-Hill, New York.

Bartolini, S., Bonatti, L., 2002. Environmental and social degradation as the engine of economic growth. Ecological Economics 43, 1-16.

Bartolini, S., Bonatti, L., 2008. Endogenous growth, decline in social capital and expansion of market activities. Journal of Economic Behavior \& Organization 67, 917-926.

Baumol, W., 1967. Macroeconomics of unbalanced growth: The anatomy of urban crisis. American Economic Review 57, 415-426.

Calderon, C., 2009. Infrastructure and growth in Africa. Policy Research Working Paper Series 4914. World Bank.

Calderon, C., Serven, L., 2010. Infrastructure in Latin America. Policy Research Working Paper Series 5317. World Bank.

Chatterjee, S., Sakoulis, G., Turnovsky, S., 2003. Unilateral capital transfers, public investments and economic growth. European Economic Review 47, 1077-1103.

EC, 2010. EUROPE 2020. A strategy for smart, sustainable and inclusive growth. Report. European Commission. Brussels. 
Echevarria, C., 1997. Changes in sectoral composition associated with economic growth. International Economic Review 38, 431-452.

Felice, G., 2011. Size and composition of public investment, structural change and growth. Departmental Working Papers 2009-28. Department of Economics, Business and Statistics, University of Milan. Milano.

Hopkins, R., 2011. The Transition Companion: making your community more resilient in uncertain times. Green Books, London.

IPCC, 2007. Fourth Assessment Report. Synthesis Report. Report. Intergovernmental Panel on Climate Change. Geneve.

Jackson, T., Victor, P., 2011. Productivity and work in the 'green economy'. Some theoretical reflections and empirical tests. Environmental Innovation and Societal Transition $1,101-108$.

Kaika, D., Zervas, E., 2013. The Environmental Kuznets Curve (EKC) theory. Part A: Concept, causes and the CO2 emissions case. Energy Policy 62, 1392 - 1402.

Lewis, W., 1954. Economic development with unlimited supplies of labour. The Manchester School 22, 139-191.

McMillan, M., Rodrik, D., 2011. Globalization structural change, and productivity growth. NBER Working Papers 17143.

Mulder, P., de Groot, H.L., 2012. Structural change and convergence of energy intensity across OECD countries, 1970-2005. Energy Economics 34, 1910 - 1921.

Ngai, R., Pissarides, C., 2007. Structural change in a multisector model of growth. The American Economic Review 97, 429-443. 
OECD, 1994. The OECD Job Study. Facts, analysis and strategies. Report. Organisation for Economic Co-operation and Development. Paris.

OECD, 2011. Towards Green Growth. Report. Organisation for Economic Co-operation and Development. Paris.

ONS, 2013. United Kingdom National Accounts. The Blue Book. Office for National Statistics.

Perée, E., Välilä, T., 2007. A primer on public investment in Europe, old and new. Economic and financial reports. European Investment Bank. London.

Pissarides, C., 2007. Unemployment and hours of work: The North Atlantic divide revisited. International Economic Review 48, 1-36.

Rockström, J., Steffen, W., Noone, K., Persson, Å., Chapin, F.S., Lambin, E.F., Lenton, T.M., Scheffer, M., Folke, C., Schellnhuber, H.J., et al., 2009. A safe operating space for humanity. Nature 461, 472-475.

Romp, W., de Haan, J., 2007. Public capital and economic growth: A critical survey. Perspektiven der Wirtschaftpolitik 8, 6-52.

Stern, N., 2006. Stern Review on the Economics of Climate Change. Report. HM Treasury. London.

Turnovsky, S., 1997. Fiscal policy in a growing economy with public capital. Macroeconomic Dynamics 1, 615-639.

UNEP, 2011. Towards a Green Economy: Pathways to Sustainable Development and Poverty Eradication. Report. United Nations Environment Programme. Nairobi. 
Van Ark, B., O’Mahony, M., Timmer, M., 2008. The productivity gap between europe and the united states: Trends and causes. Journal of Economic Perspectives 22, 25-44.

Van Ark, B., Woltjer, P., 2008. The EU KLEMS Productivity Report. Report. Groningen Growth and Development Centre. Groningen.

Voigt, S., Cian, E.D., Schymura, M., Verdolini, E., 2014. Energy intensity developments in 40 major economies: Structural change or technology improvement? Energy Economics $41,47-62$.

World Bank, 1994. World Development Report 1994. Infrastructure for Development. Report. World Bank. Washington D.C.

World Bank, 2012a. Inclusive Green Growth. The Pathway to Sustainable Development. Report. World Bank. Washington D.C.

World Bank, 2012b. Transformation through infrastructure. Infrastructure Strategy update FY2012-2015. Report. World Bank. Washington D.C. 